\title{
The Effect of Functional Play towards Gross Motor Skill for Children with Autism
}

\author{
Susi Marta Handayani, Sudarsini, Endro Wahyuno \\ Universitas Negeri Malang, Indonesia \\ E-mail : susi145marta@gmail.com
}

\begin{abstract}
The development of gross motor skill for children with autism mostly is not appropriate with their chronological age. Particularly, it is occurred to the coordination ability such as throwing and catching ball, which emphasized on the strength, endurance, and movement direction. This research was conducted by using Single Subject Research method with A-B-A design and using frequency and percentage as measurement unit. The research subject was a child with mild autism. The research result showed that: mean level of mean improved from baseline-1 of $31.32 \%$, intervention of $61.7 \%$, and baseline-2 of $82.15 \%$. Data of overlap percentage between baseline-1 and intervention condition was $0 \%$. Functional play could improve gross motor skill in throwing and catching ball in the strength, endurance, and movement direction. Therefore, functional play - sitting and lying on the gym ball - could be made as recommendation in improving or optimizing gross motor skill such as throwing and catching ball to the children with autism.
\end{abstract}

Keywords: functional play, gross motor skill, throwing and catching ball, child with autism spectrum disorder

Moving and playing are activity that mostly loved by children. In the children activities, absolutely, it cannot be separated from the use of their body parts. Every child has different ability in functioning their body parts (limbs). Through playing activity, it can assist basic movement mastery such as crawling, jumping, running, throwing, and so on. Playing activity is also able to improve better physical condition elements such as speed, strength, endurance, elasticity, balance, and so forth.

Children with autism included into Children with Special Needs who have neuro-biological disorder with the constraint of brain nerve function which related to the communication, motor, social, and attention function. Autism is complex developmental disorder in which the symptoms including the difference and inability in various aspects such as social communication, gross motor skill, soft motor skill, and also inability to perform social interaction. Children with autism commonly conduct repeated action such as clapping hand, moving around, running back and forth, and so on. Such the children in their age, children with autism also love to play game, although their movement seems imperfect. One of movement that can be seen when the children with autism do playing is ability in throwing and catching. There are children with autism who have good motor coordination; however, they infrequently have bad motor coordination such as they are unable to play throwing-catching game. Children with autism have difficulty in coordinating and planning their movement such as throwing and catching movement
(Konggres Nasional Autisme Indonesia, 2003).

As with the development of gross motor skill in the age of 0-7 years old, throwing ability start in the age less than 1 year, while catching ability start in the age of 2 years old. These abilities are well-developed in the age of 6 years old where the children are able to throw and catch the ball for the distance of 2 meters (Age, 2012). In this developmental step, it shows that children have owned good shoulder stability and good coordination, thus the children are able to perform throwing and catching activities accurately, with appropriate movement direction and adequate strength.

Throwing and catching are both of gross motor skill movement. This movement needs the work of body's upright muscles, which are back, arm, and hand muscle. It is in line with the statement of Sukamti (2007) that gross motor skill movement is ability which needs most of children's body part coordination. Gross motor movement involves large muscles such as hand muscle, arm muscle, leg muscle, and the whole children's body. Activities which use large muscles are non-locomotor skill movement, locomotor movement, and manipulative movement. Non-locomotor movement is movement activity that performed without moving body to the other place, for example, pushing, folding, pulling, and bowing. Locomotor movement is movement activity that performed by moving body from one place to another, for example, running, jumping, walking, and so on. While, manipulative movement is manipulation movement activity, for example, throwing and catching. 
Throwing and catching ball activity is manipulative non-locomotor movement. Throwing and catching ball activity performed by large muscles in the arm and hand area and also need back muscle in the upright position. These activities need strength and endurance from shoulder and arm muscles. Strength is skill of certain muscular group to generate energy during contraction. Endurance is certain muscular or muscular group ability to endure an activity in certain times.

According to Rehuluna (2013), throwing and catching ball by using both hands are bilateral coordination, which is ability to use both sides of body in the same time where those both sides of body are controlled and coordinated. Coordination ability affected by postural (core) control and shoulder stability. Postural (core) control is ability to keep the body in controlled position when it is in contrast with gravity. Good postural control is necessary to determine stable position in the arm and leg movement and to keep the head in optimal position. Whereas, shoulder stability refers to the ability of shoulder joint muscles to keep the shoulder in stable position. Shoulder control is ability to move hand in controlled and accurate way.

Condition of gross motor skill towards children with autism in the Service Center for Children with Autism (Pusat Layanan Anak Autis) at second semester academic year of 2014-2015 showed various types. Many children seemed to have gross motor development as with their actual age, thus the children were able to do coordinated movement. Some children had gross motor ability that not appropriate with their chronological age. Their gross motor skill was under their chronological age development. For example, there was 6 years old child with autism who owned gross motor development such 3 years old child. Children that actually should be able to jump and walk on narrow road still have difficulty to do these activities. The same thing for throwing and catching ability, their movement seems rigid and weak. Throwing and catching movement are lack of coordination and weak strength in throwing movement.

According to Brower (2007), children with autism, in general, have lower motor skill than their peers, both qualitatively and quantitatively. One indicator of motor disorder or motor clumsiness, in the case of children with autism, showed by lack of ability in motor activities, particularly for tasks which need complex motor coordination and movement skill, for instance is activity of throwing and catching ball.

Frequent and fun training will be able to assist in strengthening children's coordination in order to do more complex activities. Fun activity for children is playing. The term of playing, basically, is an activity that conducted repeatedly solely for fun and there is no goal or target.

Functional play is playing activity expected to be foundation for more complex (integrated) gross motor skill. Functional play is an activity that characterized by repeated muscular movement. According to Johnson (Triharso, 2013), this kind of playing activity is called as motor play because it needs motor or physical skill. Functional play can improve physical, muscular strength, and gross motor skill. Sutadi, Bawazir, \& Tanjung (2003) state that functional play can be defined as children who use repetition in physical, language, and something manipulation action, based on their needs on physical activities. Many elements of playing in the playground can be seen as functional play. Repeatedly perform sliding activity, playing seesaw, swing away, and bounce back sitting on gym ball can be considered as functional play due to those activities conducted in repetition. Activities that can be performed with gym ball are sitting, lying on the stomach, and lying on the back over the ball. Therefore, functional play using gym ball, repeated movement in the sitting and lying position can be fun playing tool for children.

Thus, elements that can be established on functional play activity, are gym ball activity including: strength, endurance, coordination, and accuracy or focus to the postural and shoulder area in order to improve bilateral coordination and motor planning. Those elements are necessary for children while they perform activity of throwing and catching ball.

\section{METHOD}

The study used experimental method with Single Subject Research (SSR) design. SSR is a method which purposes to obtain data by observing whether any effect of intervention. SSR design used in this research was A-B-A. The research subject was a child with special needs, which was a 7 years old male child with mild autism.

In this research, the independent variable was functional play. This research used medium gym ball playing tool with diameter of 1 meter. The child have got intervention by sitting and lying on the stomach over the gym ball. The dependent variable was the child's gross motor skill, which was ability in throwing and catching ball where the indicators of throwing were throwing ball to the front, throwing ball upward, throwing ball to the right side, throwing ball to the left side, and throwing ball backward. While, the indicator of catching ball was catching ball from the front side. Aspects that became assessment goal were strength, endurance, and accuracy as well as movement direction in throwing and catching ball. 
Table 1. Data Recapitulation of Research Result of the Gross Motor Skill towards Child with Autism

\begin{tabular}{clll}
\hline Condition & Day to- & Total & Percent \\
\hline & 1 & 9 & $30 \%$ \\
& 2 & 9 & $30 \%$ \\
& 3 & 10 & $33,3 \%$ \\
A1 & 4 & 10 & $33,3 \%$ \\
& 5 & 9 & $30 \%$ \\
\hline \multirow{4}{*}{ B } & 6 & 14 & $46,6 \%$ \\
& 7 & 12 & $40 \%$ \\
& 8 & 18 & $60 \%$ \\
& 9 & 18 & $60 \%$ \\
& 10 & 22 & $73,3 \%$ \\
& 11 & 23 & $76 \%$ \\
& 12 & 23 & $76 \%$ \\
\hline \multirow{4}{*}{ A2 } & 13 & 23 & $76 \%$ \\
& 14 & 25 & $83 \%$ \\
& 15 & 25 & $83 \%$ \\
& 16 & 26 & $86,6 \%$ \\
\hline
\end{tabular}

Graph 1. Trend Estimation for Baseline-1 (A1), Intervention (B), and Baseline-2 (A)

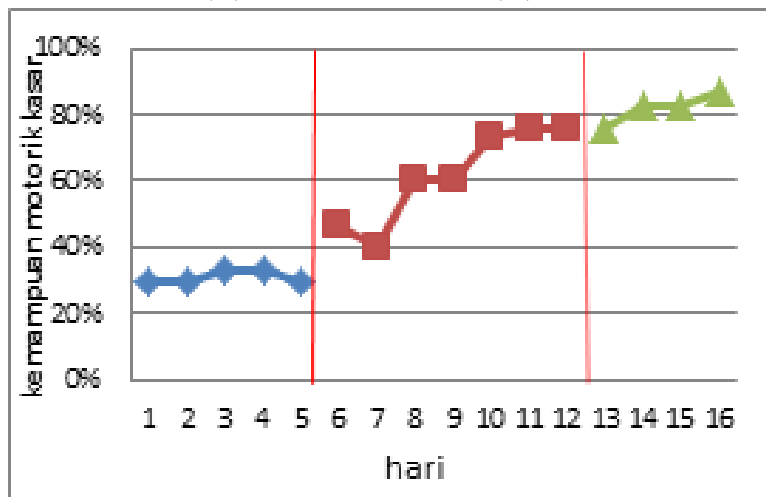

The research instrument was assessment sheet of action test to observe and measure child's gross motor skill while he performed activity of throwing and catching ball. In the baseline-1 (A1), the researcher gave score based on total number of throwing ball to the front, upward, backward, to the right side, and to the left side that could be performed by the child in 5 repetitions (5 experiments). Minimum distance that expected in this research was 2 meters from child's standing position. Whereas, for throwing ball to the right side, left side, upward, and backward, repetition for more than 5 times was considered. In the activity of catching ball, it was measured by how many times in 5 repetitions the child was able to catch the ball with the distance of 2 meters. The ball used in this research was rubber ball with diameter of $20 \mathrm{~cm}$. In the intervention condition (B), the given intervention was sitting on the gym ball with bounce back movement, sitting on the gym ball with back and forth movement repeatedly thus the child tried to maintain his position by holding on the ball. Then the child was lying on the stomach over the gym ball with the stomach on the gym ball and the ball was moved back and forth repeatedly. When the gym ball moved to the front, child's arm should be straight backward with the palm touched mattress, thus the child's weight would be on his shoulder. In the baseline-1 (A1), the researcher gave score based on total number of throwing ball to the front, upward, backward, to the right side, and to the left side as well as catching ball accurately that could be performed by the child in 5 repetitions. The obtained data then converted in percentage $(\%)$.

Analysis used in this research was analysis in condition and analysis among conditions. Change analysis in condition is analyzing the change of data in a condition such as baseline condition or intervention condition. Analysis among conditions is analyzing the change of data among conditions such as from baseline to intervention condition.

\section{FINDINGS AND DISCUSSION}

\section{Findings}

SSR design used in this research was A-B-A. This design consisted of 3 conditions. The first was, baseline-1 condition (A1) in which student's initial ability was measured without any interventions with the duration of 5 sessions. The second was intervention condition (B) in which the researcher gave intervention to the subject with the duration of 7 sessions. The third was baseline- 2 condition (A2) in which student's final ability was measured in many sessions without any interventions with the duration of 4 sessions. Table 1 is data from research result in percentage. The following is the result of data analysis.

\section{Analysis in Condition}

Condition that would be analyzed was Baseline-1 (A1), Intervention (B), and Final condition without any interventions (A2). The analysis components as follow:

Duration in the baseline-1 phase (A1) was 5 sessions, intervention phase (B) was 7 sessions, and baseline-2 phase (A2) was 4 sessions.

Baseline-1 condition (A1) had the estimation of upward trend due to score in that condition showed the improvement although the score difference was not too large. In the intervention condition (B), the estimation was upward trend due to the score in that condition showed various improvements. It means that subject had gross motor improvement after given by intervention of functional play using gym ball. Line in the baseline- 2 condition (A2) had estimation of upward trend. 
Graph 2. Trend Stability for Baseline-1 (A1), Intervensi (B), and Baseline-2 (A)

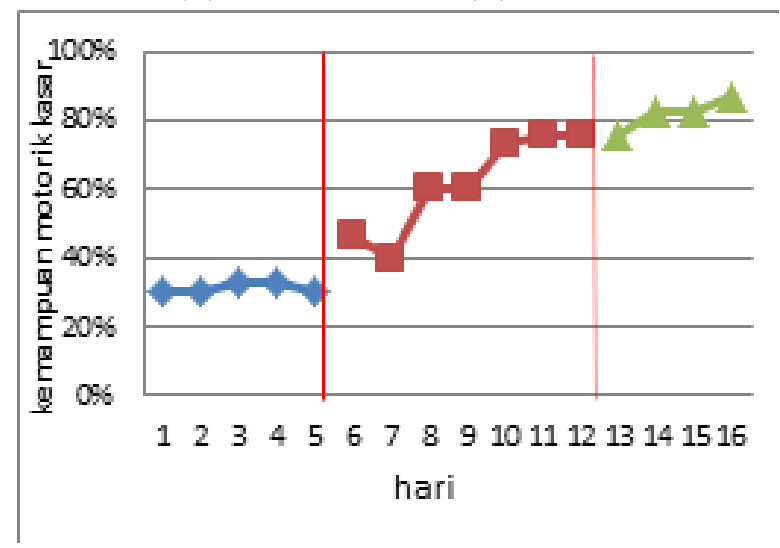

Tabel 2. Visual Analysis Result in Each Condition

\begin{tabular}{llll}
\hline Condition & A & B & A2 \\
\hline $\begin{array}{l}\text { Duration } \\
\text { Trend Esti- }\end{array}$ & 7 & 4 \\
mation & $(+)$ & $(+)$ & \\
Trend Stabil- & & & \\
ity & & variable & stable \\
Data Record & & & \\
& & & \\
Stability and & & \\
Range Level \\
The Change & $30 \%-30 \%$ & $76 \%-46,6 \%$ & $86,6 \%-$ \\
of Level & $(0 \%)$ & $(+29,4 \%)$ & -------- \\
& & & $(+10,6 \%)$ \\
\hline
\end{tabular}

Graph 3. Data of overlap condition from intervention to the baseline-1 (A1) condition

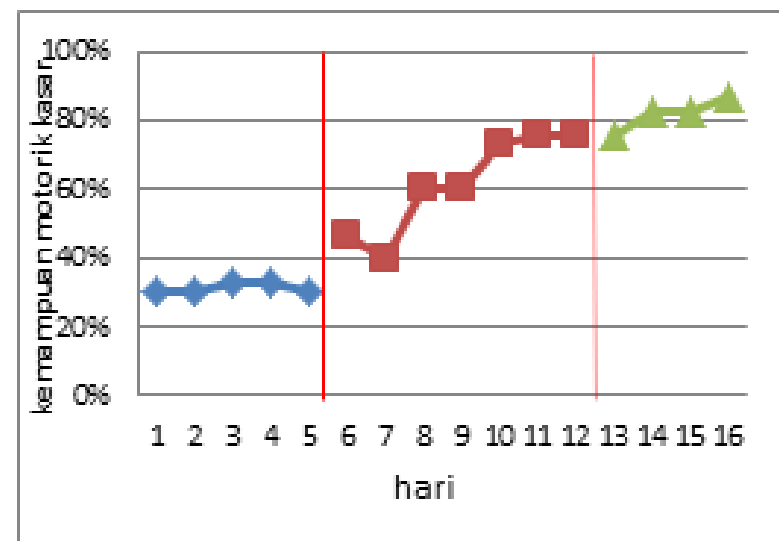

In determining trend stability, this research used stability criteria of $15 \%$ (Sunanto et al., 2005). The result of each condition as follows: (1) stability range in the baseline-1 (A1) was 4.9; mean level was 31.32, upper limit was 33.81 and lower limit was 28.8. Thus the trend stability in baseline-1 condition (A1) was $100 \%$, in which it means that the data was stable. (2) Stability range in the intervention (B) was 11.4; mean level was 61.7 , upper limit was 67.2 and lower limit was 56 . Thus the trend stability in intervention condition (B) was $28.5 \%$, meaning that the data was unstable (variable). (3) stability range in the baseline-2 (A2) was 12.9; mean level was 82.1, upper limit was 88.64 and lower limit was 75.66. Thus the trend stability in baseline-2 condition (A2) was $100 \%$, meaning that the data was stable. The following is graph of trend stability for those three conditions in Graph 2.

In the baseline- 1 condition (A1), data record showed by upward $(+)$ trend. Intervention condition (B) had upward $(+)$ trend, and also the same for baseline-2 condition (A2) due to the score that obtained by subject improved.

Data in the baseline- 1 condition (A1) was taken with range of $30 \%-33.3 \%$ with flat trend score. In the intervention condition (B), it had score improvement with the range of $40 \%-76 \%$, meaning that, the data was unstable. While in the baseline-2 condition (A2), the score had improvement with the range of $76 \%-86.6 \%$.

Baseline-1 (A1) condition showed equal $(=)$ meansing flat, intervention condition (B) had improvement thus the data showed positive $(+)$, while in the baseline-2 condition (A2), it had score improvement thus the data showed positive $(+)$.

The following is Table of analysis result for those three conditions, show in table 2 .

\section{Analysis among Conditions}

Analysis among conditions is the change of data among conditions. Components to the data analysis among conditions as follows. Number of variable that would be changed from baseline-1 condition (A1) to intervention condition (B) and from intervention (B) to baseline-2 (A2) was one (1), gross motor skill towards child with autism. Trend between baseline-1 condition (A1) to intervention (B) and from intervention (B) to baseline-2 (A2) was upward trend (improved). It means that target behavior improved after given by intervention. The change of trend stability between baseline-1 (A1) to intervention (B) was stable to variable. While, trend stability from intervention (B) to baseline-2 (A2) was variable to stable.

Gross motor skill in the baseline-1 (A1) condition to intervention (B) had difference of $16.6 \%$. It showed that the intervention was affected to the target behavior. While, gross motor skill in the intervention (B) to baseline-2 (A2) had no difference with the obtained data of $0 \%$. 
Table 3. Result of Analysis among Conditions

\begin{tabular}{|c|c|c|}
\hline $\begin{array}{l}\text { Compared } \\
\text { condition }\end{array}$ & $\mathrm{B}$ to $\mathrm{A} 1$ & $\mathrm{~B}$ to $\mathrm{A} 2$ \\
\hline $\begin{array}{l}\text { Number of } \\
\text { Changed } \\
\text { Variable }\end{array}$ & 1 & 1 \\
\hline \multirow[t]{2}{*}{$\begin{array}{l}\text { The Change of } \\
\text { Trend and Its } \\
\text { Effect }\end{array}$} & $(+)$ & $(+)$ \\
\hline & $(+)$ & $(+)$ \\
\hline $\begin{array}{l}\text { The Change of } \\
\text { Trend Stability }\end{array}$ & $\begin{array}{l}\text { Stable to } \\
\text { variable }\end{array}$ & Variable to stable \\
\hline $\begin{array}{l}\text { The Change of } \\
\text { Level }\end{array}$ & $16.6 \%$ & $0 \%$ \\
\hline $\begin{array}{l}\text { Overlap } \\
\text { Percentage }\end{array}$ & $0 \%$ & \\
\hline
\end{tabular}

Data of overlap percentage from intervention (B) to baseline-1 (A1) was $0 \%$. Based on the result of overlap percentage, this data of $0 \%$ showed that the intervention - functional play by using gym ball - was affected to the improvement of gross motor skill, which was throwing and catching ball. The following is the result of analysis among conditions, show in table 3.

\section{Discussion}

Based on the analysis result of processed data, it was found that, overall, functional play by using gym ball which aims to improve gross motor skill had positive effect to the improvement of gross motor skill towards child with autism. From the obtained data, the subject could throw ball in the distance $<1$ meter and the higher frequency of repetition resulted in weaker subject's strength in throwing ball, the distance and throwing direction became more inappropriate as what's expected. In his activity, the subject should be directed for most of times both visually (imitating the researcher) and verbally. The subject had difficulty in throwing ball upward in which the throwing direction tended to the front. Posture in throwing ball to the right and left side still needed to be corrected and directed. In catching ball in the distance of 2 meters, the subject still had difficulty.

This finding is supported by Johnson (cited in Triharso, 2013) and Tedjasaputra (2001). According to Johnson (Triharso, 2013), functional play is playing activitey expected to be foundation for more complex (integrated) gross motor skill, characterized by repeated muscular movement. This activity is called as motor play because it needs motor or physical skill. It can improve physical, muscular strength, and gross motor skill. Tedjasaputra (2001), state that functional play can be defined as children who use repetition in physical, language, and something manipulation action, based on their needs on physical activities. Repeatedly perform sliding activity, playing seesaw, swing away, and bounce back sitting on gym ball can be considered as functional play due to those activities conducted in repetition. Therefore, functional play using gym ball, repeated movement in the sitting and lying position can be fun playing tool for children.

In the condition of intervention, which was through activity of sitting and lying on gym ball, it showed improvement to the gross motor skill with the indicator of result for throwing ball upward, backward, to the right side, to the left side, and catching ball. It was showed through the result of analysis in condition. Trend estimation in intervention condition (B) showed an improvement. The change of level in the intervention condition (B) and baseline-2 condition (A2) showed positive $(+)$ result. In the phase of baseline-1 (A1), mean level was $31.32 \%$ and then improved in the phase of intervention (B) with mean level of $61.7 \%$ and phase of baseline-2 (A2) with mean level of $82.15 \%$. It showed that functional play by using gym ball could be affected to the improvement of subject's gross motor skill. The result of analysis among conditions showed that the research subject had improvement in the baseline-1 (A1) to intervention (B) and from intervention (B) to baseline-2 (A2). The researcher did not see overlap the data from intervention (B) to baseline-1 (A1). Overlap percentage from this research was $0 \%$. The smaller overlap, the better effect of intervention to the target behavior (Sunanto et al., 2005). Based on the data analysis that been explained above, it could be proved that the effect of intervention by using functional play activity could improve gross motor skill towards child with autism in which before intervention the research subject had difficulty in throwing and catching ball, especially in the endurance and strength. The research subject was able to throw ball to the front with the distance of 2 meters in proper posture for 5 times. The subject could throw ball upward, backward, to the right side, and left side. The subject was able to catch ball with the distance of 2 meters. Subject's endurance and strength showed improvement as well as there was an improvement for posture and direction. Therefore, it means that subject could meet success criteria.

\section{CONCLUSION AND SUGGESTION}

\section{Conclusion}

This research aims to know the effect of functional play by using gym ball towards the gross motor skill, in the term of throwing and catching ball. Based on characteristic found in the study, it showed that subject's gross motor skill, particularly movement which needs 
optimal postural control, still inappropriate in stability and shoulder control. The subject's gross motor skill, which was throwing and catching ball, showed improvement as follows: (1) Child's ability in throwing ball to the front, upward, backward, to the right side, and left side showed improvement in endurance, strength, and movement accuracy. (2) Ability in catching ball with the distance of 2 meters showed improvement in agility. (3) Functional play through repeated movement - by sitting and lying on gym ball - could improve postural control ability, stability, and shoulder control. Postural control is necessary to perform upright position, while stability and shoulder control are necessary to manage strength, endurance, and movement direction. Postural control, stability, and shoulder control are important element/component in gross motor skill of upper body parts such as arm and hand. It means that functional play by using gym ball could improve gross motor skill towards children with autism.

\section{Suggestion}

For the school teacher, it is suggested to make finding can be used as reference for overcoming student's problems, especially gross motor problem in throwing and catching ball. For the next researcher, it is suggested to make this research result as guidance to find new invention in order to develop this research or the next researcher can use this research in testing other children, even not children with autism.

\section{REFERENCE}

Age, P. (2012). Pengantar Dasar Tumbuh Kembang Anak. Seminar dan Workshop Pusat Layanan Autis kota Malang.

Brower, F. (2007). 100 Ide Membimbing Anak Autis. Penerjemah: Novita Heny. Jakarta: Essensi Erlangga Group.

Rehuluna, M. (2013). Pemrosesan Sensori Dan Kemampuan Motorik. Malang : Seminar dan workshop Pusat Layanan Autis Nasional.

Sutadi, R., Bawazir, L. A., Tanjung, N. (2003). Konggres Nasional Autisme Indonesia. Penatalaksanaan Holistik Autisme. Jakarta: Pusat Informasi dan Penerbitan Universitas Indonesia

Sukamti. (2007). Diktat Perkembangan Motorik. Yogyakarta: FIK UNY

Sunanto, Juang., Takeuchi, Koji., \& Nakato, H. (2005). Pengantar Penelitian dengan Subjek Tunggal. CRICED University of Tsukuba.

Tedjasaputra, M. S. (2001). Bermain, Mainan dan Permainan. Jakarta: Grasindo

Triharso, A. (2013). Permaianan Kreatif Educative Anak Usia Dini. Yogjakarta: C.V Andi offset.

Universitas Negeri Malang. (2010). Pedoman Penulisan Karya Ilmiah; skripsi, tesis, disertasi, artikel, makalah, tugas akhir, laporan penelitian. Malang: Universitas Negeri Malang.

Veskarisyanti. A., Galih. (2008). 12 Terapi Autis Paling Efektif \& Hemat Untuk Autisme, Hiperaktif, Retardasi Mental. Yogyakarta: Pustaka Anggrek. 